CLAUDIA MENDOZA

\title{
LLAMADOS A TRANSFORMAR EN VIDA EL SUFRIMIENTO Y LA MISMA MUERTE HACIENDO -Y DICIENDO- EL BIEN Reflexiones a propósito de la pasión de Cristo y del sufrimiento por ser cristiano según la primera carta de Pedro
}

\section{Resumen}

El artículo se centra en 1 Pe 3,17-22 y su enigmática referencia a los "espíritus encarcelados", entendido como una fundamentación cristológica a la exhortación a afrontar activamente, "haciendo" y "diciendo" el bien sin reservas, el proceso de padecimiento y rechazo al que el bautizado se ve sometido por su propio compromiso y fidelidad.

Palabras clave: 1 Pedro. Espíritus encarcelados. Padecer por hacer el bien. Poder regenerador de la Palabra. Bendecir. Compromiso bautismal.

Él pasó haciendo el bien

(Hch 10,38)

La primera carta de Pedro es el único texto neotestamentario que, en el marco de una "exhortación a los esclavos" (1 Pe 2,18-25), insinúa una "soteriología de la pasión" en el sentido más estricto del término, es decir, afirmando el carácter salvífico del sufrimiento de Jesús de Nazaret -del Jesús "terreno", de su dolor, de sus heridas, de sus llagas, de su actitud y comportamiento ante los que lo injuriaban y maltrataban- sin mencionar explícitamente, en ese contexto específico, ni su muerte ni su resurrección. En una clara instrucción a las personas más vulnerables de esa sociedad sobre el "sufrimiento injusto" (padecido obrando el bien, en unión con Dios y por la sola razón de ser cristianos -cf. 1 Pe 4,15-16-), este texto afirma, 
de manera muy singular, que el sufrimiento -vicario- padecido "activamente" por Jesús tiene sentido y "cura", libera de los pecados (cf. 2,24).

Este motivo del "padecer salvífico" de Cristo "haciendo el bien" no siempre ha sido conectado con suficiente claridad con la unidad literaria 3,17-22 y su enigmática referencia al "anuncio de Cristo" a "los espíritus encarcelados", quizá por ser este un pasaje que ha estado siempre "en el ojo del huracán", al haber estado vinculado desde los albores del cristianismo -adecuada o inadecuadamente- al artículo de fe "descendió a los infiernos" 1 .

1 Si bien algunos importantes especialistas sostienen que la fórmula "descendió a los infiernos" no puede ser constatada en Símbolo alguno antes del siglo IV, el Catecismo de la Iglesia católica dice en el n. 632: "Las frecuentes afirmaciones del Nuevo Testamento según las cuales Jesús 'resucitó de entre los muertos' (Hch 3,15; Rom 8,11; 1 Cor 15,20) presuponen que, antes de la resurrección, permaneció en la morada de los muertos (cf. Heb 13,20). Es el primer sentido que dio la predicación apostólica al descenso de Jesús a los infiernos; Jesús conoció la muerte como todos los hombres y se reunió con ellos en la morada de los muertos. Pero ha descendido como Salvador, proclamando la buena nueva a los espíritus que estaban allí detenidos (cf. 1 Pe 3,18-19)". Cf. F. SPITA, Christi Predigt an die Geister 11 Petr. 3,19 ff.), Göttingen 1890; J. ChalnE, “La descente du Christ aux Enfers", en L. PIRot (ed.), Dictionnaire de la Bible Supplément II, Paris 1934, 395-430; W. BIEDER, Die Vorstellung von der Höllenfahrt Jesu Christi. Beitrag zur Entstehungsgeschichte der Vorstellung vom sog. Descensus ad inferos, Zürich 1949; B. REICKE, The Disobedient Spirits and Christian Baptism. A Study of I Peter III,19 and its Context, Kovenhaven 1946; A. Grillmeler, “Der Gottessohn im Totenreich. Soteriologische und christologische Motivierung der Descensuslehre in der älteren christlichen Überlieferung", ZKTh 71,1 (1949) 1-53; J. N. D. Kelly, Early Christian Creeds, London 1950; J. Galot, "La descente du Christ aux enfers", NRT 83/5 (1961) 469-491; W. J. DaLton, Christ's Proclamation to the Spirits: A Study of 1 Peter 3:18-4:6, Rome 1965; R. N. LongenECKER, The Christology of Early Jewish Christianity, London 1970; H. MANKE, Leiden und Herrlichkeit. Eine Studie zur Christologie des I. Petrusbriefe, Münster i. W. 1975; H. J. VoGELS, Christi Abstieg ins Totenreich und das Leuterungsgericht an den Toten. Eine bibeltheologischdogmatische Untersuchung zum Glaubensartikel "descendit ad inferos", Freiburg i.B. 1976; K. SHIMADA, "The Cristological Credal Formula in 1 Peter 3,18-22 Reconsidered", AnJapB 5 (1979) 154-176; Ch. PerRot, "La descente aux enfers et la prédication aux morts", en ID. (ed.), Études sur la première lettre de Pierre, Paris 1980, 231-246; W. MAAS, “'Descendió a los infiernos'. Aspectos de un artículo de fe olvidado", Communio 3 (1981) 69-86; N. Brox, “Excursus: El 'descenso a los infiernos' de Cristo (los avatares de 1 Pe 3,19s.; 4,6", La primera carta de Pedro, Salamanca 1994, 245-254; P.-G. KLUMBIES, “Die Verkündigung unter Geistern und Toten nach 1Petr 3,19f und 4,6", ZNW 92 (2001) 207-228; J. D. M. Derret, "He Descended into Hell”, JHC 9/2 (2002) 234-245; D. Rudman, "1 Peter 3-4 and the Baptism of Chaos", en J. Schlosser (ed.), The Catholic Epistles and the tradition, Leuven 2004, 397-405; M. Williams, "1 Peter 3:18a-c: 'Christ's suffering as sacrificial'”, The Doctrine of Salvation in the First Letter of Peter, Cambridge 2011, 117-126. 
Proponemos a continuación 1) una traducción de 1 Pe 3,17-22, y 2) un comentario de algunas ideas inspiradas en ese pasaje y su contexto, en orden a intentar destacar su función explicativa en el desarrollo de la argumentación -de peculiar lógica, por cierto-en términos, según entendemos, de una fundamentación cristológica a la exhortación general precedente a "no devolver mal por mal" -especialmente al mal que se realiza con la palabra- (3,8-12) y a empeñarse en hacer el bien, aunque sea causa de sufrimiento injusto (3,13-16), superando las fronteras del tiempo, del espacio y del ámbito de lo meramente humano. Al final del recorrido, 3) aventuraremos algunas reflexiones.

\section{Algunas cuestiones de crítica textual, discusión y precisión de algunos términos y sugerencia de traducción}

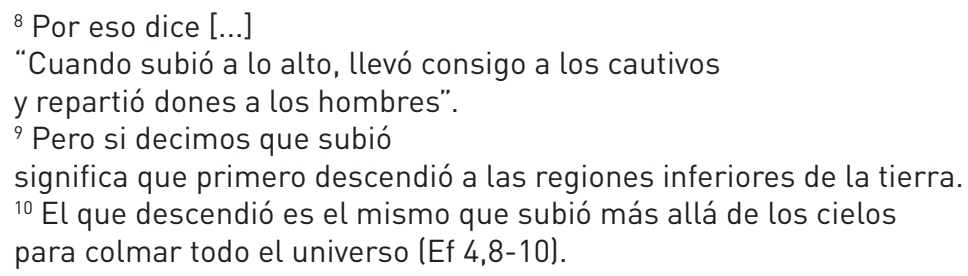

Propondremos primero (1.1) una traducción de 1 Pe 3,17-22, explicando y fundamentando nuestras opciones en nota a pie de página, a fin de aligerar la lectura de la misma. Indicaremos a continuación (1.2) nuestra propuesta de interpretación de los "espíritus encarcelados" mencionados en 1 Pe 3,19.

\subsection{Traducción de 1 Pe 3,17-22}

1 Pe 3,17-22², según entiende Cervantes Gabarrón ${ }^{3}$, es una única oración (lo que no queda reflejado en la mayoría de las traducciones del texto sagrado) muy compleja, formada por una sucesión encadenada e ininterrumpida de subordinadas dependientes de 3,17, la oración principal de la unidad -una oración predicativa comparativa, sin verbo explícito,

2 La unidad literaria 3,17-22 queda delimitada por tres "inclusiones":

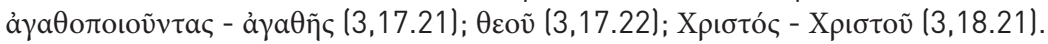

3 J. Cervantes Gabarrón, La pasión de Jesucristo en la primera de Pedro. Centro literario y teológico de la carta, Estella 1991, 186. 


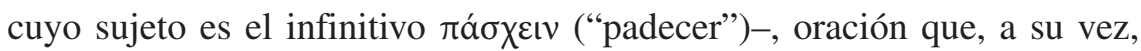
está coordinada con la frase anterior a través de la conjunción causal yá $\rho$ ("pues") y con la frase posterior mediante la conjunción causal ǒ ı ("porque").

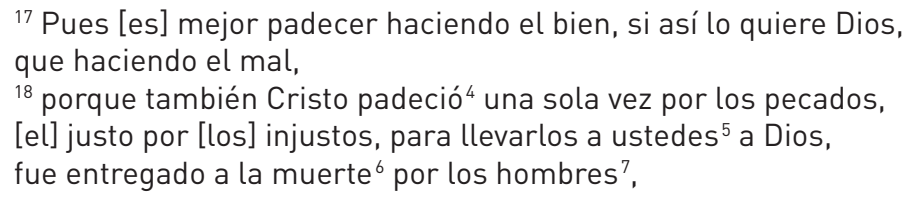

4 "Padeció" (ع̈đa $\theta \varepsilon v$ ). Los manuscritos más antiguos y otros testigos de un área

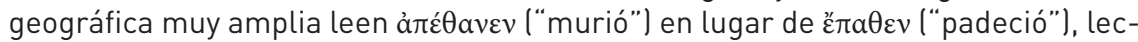
tura que aparece recién en documentos más tardíos (por ejemplo en "B"). Ambas lecturas resultan legítimas, lo que queda reflejado claramente en los comentarios y en las traducciones modernas. Con Cervantes Gabarrón, La pasión de Jesucristo,

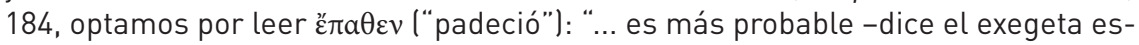
pañol- que fuera el mismo autor quien transformara una fórmula ya acuñada en la Iglesia primitiva por un interés específico en destacar el tema del sufrimiento me-

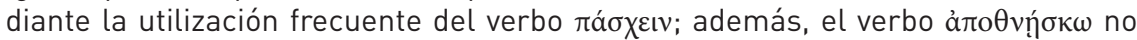
aparece en ningún otro lugar de la carta". Así también M. WiLliams, The Doctrine of Salvation in the First Letter of Peter (Society for the New Testament Studies, Monograph Series 149), Cambridge 2011, 118: "While a great majority of texts read that Christs 'died' [...] rather than 'suffered' [...] the latter is in agreement with both the immediate context [...] as well as the overall thematic emphasis on suffering that pervades the letter, and so is preferred. In any case, this reference to his suffering also includes reference to his dead".

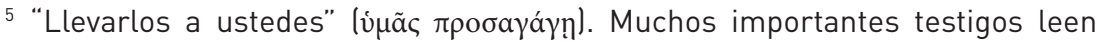

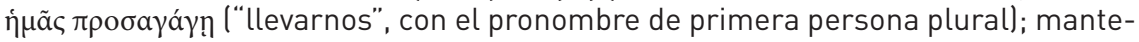
nemos la segunda persona plural, como en 3,21 y en el contexto general, que corresponde a la forma del trato epistolar (cf. Brox, “Excursus”, 226).

6 "Fue entregado a la muerte" ( $(\theta \alpha v a \tau \omega \theta \varepsilon$ ćc). Se trata de un participio aoristo pasivo del verbo Gavatów que significa "dar muerte". Es decir, el verbo no se refiere a una "muerte natural", sino a "ser llevado a la muerte por alguien". En el NT, el verbo $\theta$ avatów se emplea once veces. En voz pasiva (cuatro veces), solo aquí hace referencia a la muerte de Cristo llos otros tres pasajes -Rom 7,4; 8,36, y 2 Cor 6,9aluden, en sentido figurado, a la muerte de los creyentes en cuanto participan en la muerte de Cristo). En voz activa y referido a la muerte de Cristo aparece en los relatos marcano y mateano “de la pasión" (Mc 14,55; Mt 26,59; 27,1). Subrayamos el matiz de "intencionalidad" del verbo, ya se utilice en sentido literal, ya en sentido figurado (cf. Cervantes Gabarrón, La pasión de Jesucristo, 233).

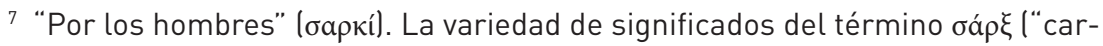
ne"), tanto en la antropología judía como en la griega, hace muy difícil precisar el sentido de бaркí, que además está en dativo. Cf. N. BRox, La primera carta de Pedro, Salamanca 1994, 226, entiende que "carne" y “espíritu” no serían categorías antropológicas, sino "ámbitos soteriológicos de lo provisionalmente perdido y de la esfera de la salvación definitiva". Teniendo en cuenta el sentido de $\pi \tilde{a} \sigma \alpha \sigma a ́ \rho \xi$ l“toda 
pero fue vivificado por [la fuerza d]el espíritu,

${ }^{19}$ por ello también?, tras haber ido,

predicó a los espíritus [que estaban] en [la] cárcel,

${ }^{20}$ a [los] que no se dejaron persuadir entonces,

cuando la paciencia de Dios esperaba ansiosamente,

en [los] días de Noé, al ser construida el arca

a causa de la que ${ }^{10}$ unos pocos, es decir, ocho personas,

carne") en 1,24 - primera aparición del término en la carta, con el sentido de "toda la humanidad"- y que бapkí se encuentra en 3,18 en una oración cuyo verbo está en voz pasiva y cuyo sujeto agente no aparece explícitamente -y no puede tratarse de un passivum divinum-, Cervantes Gabarrón, La pasión de Jesucristo, 235 (cf. 187 y

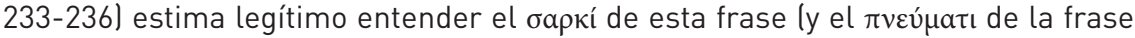
paralela siguiente) como un dativo agente: "Con la provisionalidad de toda hipótesis, nos parece oportuno [...] proponer бapkí como dativo agente del participio pa-

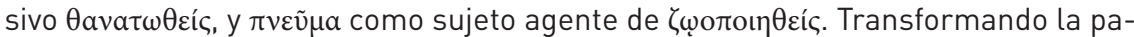
siva en activa, en castellano se podría interpretar: El hombre le daba la muerte y el espíritu le daba la vida. Pensamos que esta interpretación es coherente con el contenido doctrinal y parenético de la carta, pues la muerte de Cristo es el momento culminante del sufrimiento provocado por otros".

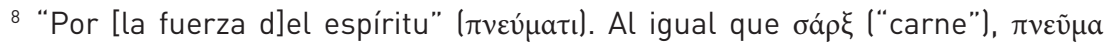
("espíritu") es también un concepto muy complejo, que además está en dativo y sin determinante alguno -a diferencia de los demás pasajes neotestamentarios, en los

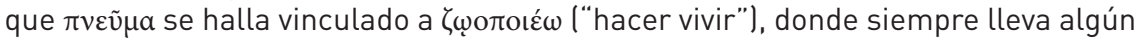
tipo de determinación (cf. Jn 6,63; Rom 8,9-11; 1 Cor 15,45 y 2 Cor 3,6). Con CervanTES GabarRón, La pasión de Jesucristo, 238, entendemos que $\pi v \varepsilon v ́ \mu a \tau$ alude aquí al "espíritu" no como "persona", sino como la fuerza de Dios que irrumpe definitivamente en la historia humana en y por la resurrección de Jesucristo -el "último Adán, espíritu que da vida" (1 Cor 15,45) - y lleva a cabo la transformación escatológica de la humanidad, “regenerándola” (cf. 1 Pe 1,3.23), colmándola de "vida divina" (cf. Jn 6,63), como potencia de la "nueva alianza" -no la de la "letra que mata", sino la "del espíritu que vivifica" (2 Cor 3,6)-.

9 “Por ello también” ( $\dot{v} v \tilde{\omega}$ Kál). Si bien la construcción ẻv $\tilde{\omega}$ consta de una preposición $(\hat{\varepsilon} v)$ y un pronombre relativo $(\tilde{\omega}$, que puede ser perfectamente referido al $\pi v \varepsilon v ́ \mu a \tau ı ~ d e ~ 3,18$, con el que coincide en caso, género y númerol, también puede ser interpretada como una construcción con valor adverbial, sea temporal ("entonces"), sea local (“en ello"), sea causal ("por eso”, “por ello”, “con lo cual”). Nos inclinamos por el valor "causal", entendiendo "que todo el contenido temático de 3,18, es decir, el acontecimiento de la pasión, muerte y resurrección de Cristo [...] es la razón por la que Cristo se dirige también a los espíritus de antaño que están en prisión. De este modo, el kaí del v. 19 significa también y [...] marcaría un crescendo en la actuación salvífica del Cristo resucitado, que se dirigiría incluso a los 'espíritus encarcelados'” (Cervantes Gabarrón, La pasión de Jesucristo, 187-188; cf. 243).

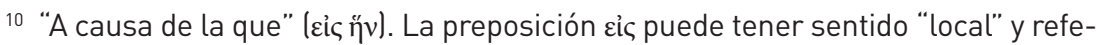
rirse al "arca", es decir, entendiendo que "el arca" sería el lugar donde ocho personas se salvaron (por ejemplo, la Biblia de Jerusalén traduce: “... en los días en que Noé construía el arca, en la que unos pocos, es decir, ocho personas, fueron salvados..."), pero también puede tener sentido "causal". El pronombre relativo femenino ᄁ๊v parece 
fueron salvados del agua ${ }^{11}$;

${ }^{21}$ aquello [era] también una figura

[de lo] que ahora los está salvando a ustedes, el bautismo ${ }^{12}$, no como una purificación de una suciedad corporal, sino como un compromiso público con Dios ${ }^{13}$

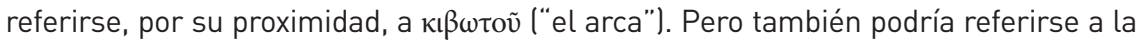

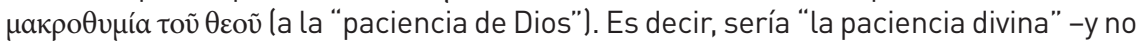
"el arca"- la causa y la razón última de la salvación tanto de Noé y su familia antes como de los cristianos ahora (cf. Cervantes Gabarrón, La pasión de Jesucristo, 188 y notas 23-25, donde señala que en 1 Pe no es extraño que el antecedente de un pronombre relativo no vaya inmediatamente antes del mismo, y donde remite a bibliografía especializada para fundamentar la interpretación "causal" de la preposición cỉc).

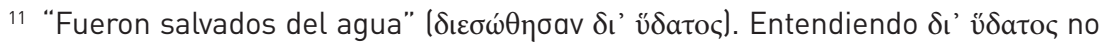
con sentido "instrumental" ("por medio de" / "a través del" agua), sino "local" (“... del agua"), ya que "el agua del diluvio es un agua destructora, mientras que la del bautismo es salvadora [...] la correlación tipológica no tiene su fundamento en los ele-

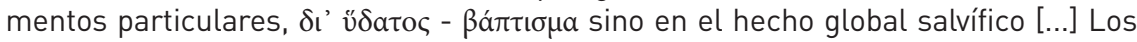
que se salvaron del agua del diluvio, gracias a la paciencia de Dios, prefiguran la salvación definitiva" (Cervantes GabarRón, La pasión de Jesucristo, 248-249 y nota 26, 189).

12 "Aquello [era] también una figura de lo que ahora los está salvando a ustedes,

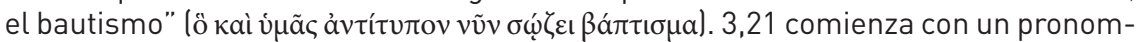

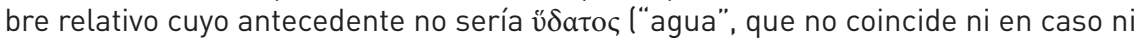
en género con el pronombre relativo inicial), sino toda la frase precedente, "que describe el acontecimiento de la salvación de ocho personas, en tiempo de Noé, en virtud de la paciencia de Dios" (Cenvantes Gabarrón, La pasión de Jesucristo, 189). La oración es muy compleja, tanto por la ausencia del verbo copulativo como por la alteración del orden sintáctico habitual y lógico (hipérbaton) -particularmente por la

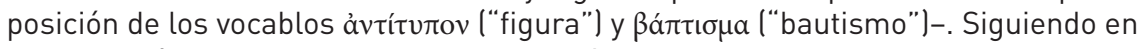
la traducción a Cervantes Gabarrón, La pasión de Jesucristo, 189 y 248-249, destacamos con él el tiempo presente del verbo $\sigma \omega \dot{\zeta} \zeta \omega$ ("salvar"), que interrumpe toda la cadena de verbos en aoristo (e imperfecto) de los versículos precedentes.

13 “No como una purificación de una suciedad corporal, sino como un compro-

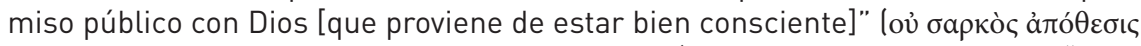

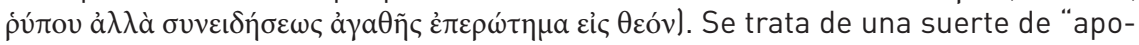
sición explicativa" de lo que, según 1 Pe, consistiría el "bautismo": no de una "re-

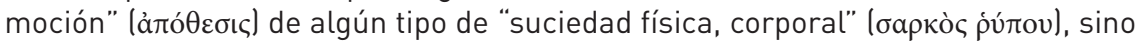

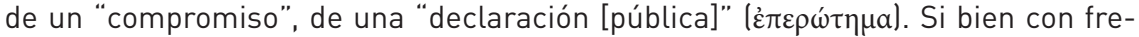

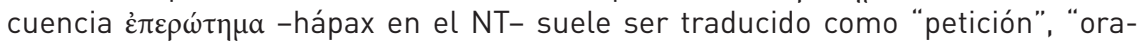
ción", "ruego" (con el sentido de "pedir a Dios una buena conciencia" o algo similar), también puede ser entendido como un "compromiso", una "declaración”, una "respuesta" en un interrogatorio, una stipulatio -en el sentido jurídico en el que se utilizó el término desde el siglo ॥, denotando un proceso que implica pregunta y respuesta para llegar a un acuerdo formal-. Con Cervantes Gabarrón entendemos que 1 Pe subraya que el bautismo es un "compromiso con Dios que brota del interior del hombre cuando experimenta la salvación en Cristo" (CERVANTES GABARRón, La pasión de Jesucristo, 249-250 y notas 269 a 272 y 275 , donde explica: “... mientras que en el NT no aparece nunca que el bautismo sea una oración, en las prácticas 
[que proviene de estar] bien consciente ${ }^{14}$ a causa de la resurrección de Jesucristo,

bautismales de la primera mitad del siglo ॥ sí se menciona el carácter de compromiso [...], mediante un juramento en el bautismo"). En esta lectura nos permitimos destacar el aspecto de "declaración pública". Así Brooks (292): "Baptism saves in

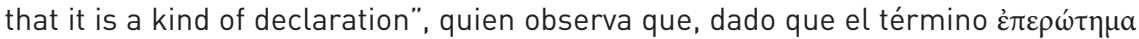
no aparece en otro lugar del NT (solo aparece en Dn 4,14, donde el contexto inclinaría a interpretarlo como "decisión"), el autor de 1 Pe lo habría elegido deliberadamente, lo que no debería ser tomado a la ligera. En esta línea, cf. también Brox, La primera carta de Pedro, 239-240: "Se han propuesto de la extraña expresión

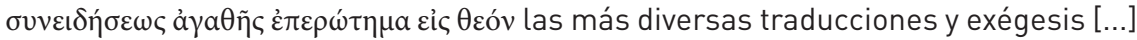

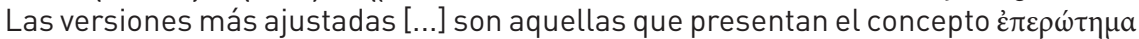
[...] en conexión con el hecho del bautismo: partiendo de la pregunta formulada al bautizado y de su respuesta, en el sentido de una promesa y compromiso moral y existencial, o de una obligación o voto. Esto se ajusta perfectamente al interés parenético de $1 \mathrm{Pe}$ ", y "puede entenderse partiendo del lenguaje contractual donde se interroga a las partes antes de cerrar el contrato" ly destaca que la corresponden-

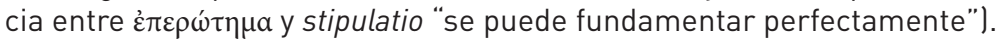

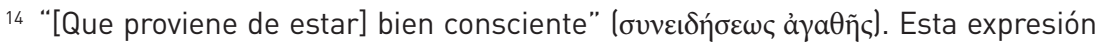
griega ("conciencia buena") es una construcción en genitivo que puede ser interpretada -en paralelo con бapkò ṕ́trov ("suciedad corporal")- como "genitivo objetivo" (es decir, como "un compromiso con Dios de mantener una buena conciencia" -o de "pedir a Dios una buena conciencia"-) o como "genitivo subjetivo" (es decir, como "un compromiso con Dios que proviene de una buena conciencia" -así la Biblia del Pueblo de Dios: "El compromiso con Dios [que surge] de una conciencia pura"-). "Conciencia"

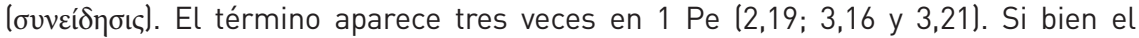

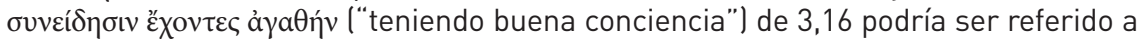

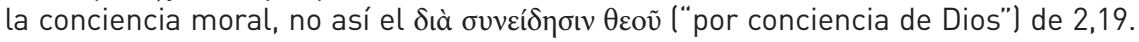
¿Qué decir de 3,21? Según Brox La primera carta de Pedro, 240, el sentido de "prome-

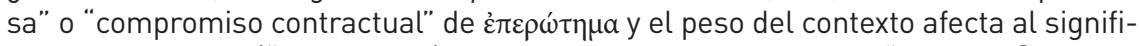

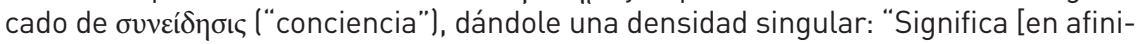
dad con 2,19 más que con 3,16] todo el compromiso de una vida nueva que $1 \mathrm{Pe}$ pretende esbozar y ejercitar de modo permanente. La adopción vinculante de este compromiso (en forma de promesa bautismal) es lo que constituye para el autor el núcleo del bautismo. [...] Se trata de una verdadera obligación (“interna”), en la línea del énfasis de 1,22s. Esta obligación debe manifestarse siempre, según $1 \mathrm{Pe}$, en comportamientos alternativos visibles". BRox, La primera carta de Pedro, 220, traduce: "Sino en el compromiso de una firme adhesión a Dios". Brooks (293-294), según el

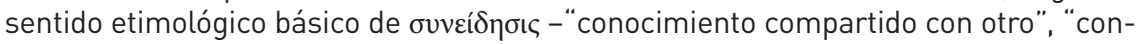
conocimiento", "con"-"ciencia"- sugiere interpretar como "estar conscientemente al tanto de una situación, circunstancia, actitud o factor importante del propio existir", lo que parece adecuado a 2,19, donde el lector es exhortado a soportar penas $\delta$ ı̀

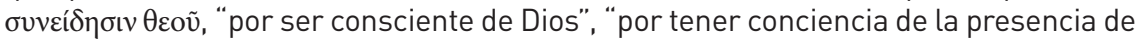
Dios en la propia vida". También en 3,16 entiende que el énfasis estaría puesto en la exhortación a permanecer conscientemente fieles mientras se padecen abusos, “dando culto al Señor en el corazón”, “dando a todo quien pida palabras de la propia esperanza" $(3,15)$. Así, el bautismo salva porque sería la declaración de conocer apropiada y conscientemente la acción salvífica de Dios por la resurrección de Jesucristo. 
${ }^{22}$ el que está a la derecha de Dios

tras haber ido al cielo ${ }^{15}$,

quedándole sometidos [los] ángeles

y [las] dominaciones y [las] potestades.

\subsection{A propósito de "los espíritus [que estaban] en [la] cárcel"}

(

Se han propuesto hipótesis de todo tipo a propósito de la identificación de estos "espíritus encarcelados". Desde la publicación en 1890 del libro de Friedrich Spitta ${ }^{16}$ se comenzaron a tener progresivamente en cuenta en orden a ello antiguas tradiciones judías respecto de la suerte de los "hijos de Dios" -interpretados en la tradición posterior como "ángeles", y a los que se califica a veces de "espíritus"- mencionados en Gn 6,1-6-texto inmediatamente precedente al relato bíblico del diluvio-, de su caída y de su castigo consiguiente, que se habrían conservado en el así llamado $L i$ bro etiópico de Henoc ${ }^{17}$.

Refiriéndose al pecado de los "hijos de Dios" que se unieron a las hijas de los hombres (cf. Gn 6,1-4), el Libro de Henoc afirma en varias ocasiones que el castigo para los "ángeles/espíritus" consistió en ser "encadenados" y retenidos en un determinado lugar de reclusión ${ }^{18}$.

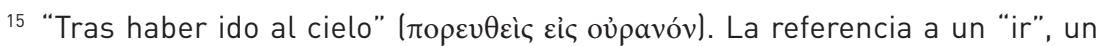
"desplazarse" de Cristo resucitado -fórmula que, para expresar la dimensión triunfante y "celestial" del Señor, es más dinámica que la de "estar a la derecha de Dios" de la frase anterior- no es tan habitual (aparece en Hch 1,10). A juicio de Brox, La primera carta de Pedro, 241, “muestra [...] que también el v. 19 hace referencia al 'viaje' de Cristo a un lugar, y este lugar no tiene por qué ser los infiernos. El lugar de los seres supraterrenos puede estar en el 'aire' (cf. Ef 2,2; 6,12), entre el cielo y la tierra, y, por tanto, 'en el camino' de Cristo, que sube al cielo. Para el v. 19 no está claro el lugar, por las diversas indicaciones del libro de Henoc, y queda abierto, sobre todo debido a lo incierto de las ideas precisas que subyacen en $1 \mathrm{Pe}$."

${ }^{16}$ Cf. nota 2, supra.

17 Cf., entre muchos otros, Brox, La primera carta de Pedro, 230-235, y KLUMBies, “Die Verkündigung”, 207-228, 10-11. El Libro / de Henoc o Henoc etiópico se citará de A. Díez Macho (ed.), Apócrifos del Antiguo Testamento, IV. Ciclo de Henoc, Madrid 1984, 39 ss.

18 HenEt 18,11-19,3 señala, por ejemplo, que ese lugar de "reclusión" se encontraría "donde se acaban los cielos y la tierra" y que "sirve de cárcel a los astros y potencias del cielo". Esta pena de "encadenamiento/cárcel” impuesta, según la tradición judía, a "los ángeles pecadores" de Gn 6,1-6 figura también en Jubileos 5,6 y en ApBar 56,13. 
Por ejemplo, en HenEt 10,4-7se lee:

Encadena a Azazel de manos y pies y arrójalo a la tiniebla; hiende el desierto que hay en Dudael y arrójalo allí. Echa sobre él piedras ásperas y agudas y cúbrelo de tinieblas; permanezca allí eternamente; cubre su rostro, que no vea la luz, y en el gran día del juicio sea enviado al fuego.

Henoc recibe el encargo de ir a comunicarles que la sentencia contra ellos es irrevocable, que no tendrán paz ni perdón:

Henoc, escriba justo, ve y haz saber a los vigilantes del cielo [...] que no tendrán paz ni remisión de los pecados [...] se lamentarán por la perdición de sus hijos y suplicarán continuamente, pero no alcanzarán misericordia ni paz (HenEt 12,4-6).

Fue Henoc y dijo a Azazel: "No tendrás paz: contra ti se ha pronunciado la grave sentencia de atarte. No alcanzarás reposo ni misericordia ni intercesión por la iniquidad que has enseñado y por los actos de blasfemia, violencia y pecado que has mostrado a los hombres" (HenEt 13,1-2s).

Henoc refiere estas cosas, y los ángeles le ruegan que interceda por ellos para que el Señor los perdone. Henoc escribe entonces "un memorial de súplica y ruego por sus almas, las acciones de cada uno y su petición para obtener perdón y descanso" (HenEt 13,6). Tras responderle el Señor en sueños, Henoc comunica a los ángeles:

Yo he escrito vuestro ruego, pero en mi visión se me ha mostrado que no os valdrá vuestra súplica en todos los días de la eternidad, pues firme es la sentencia contra vosotros: no tendréis paz. Ya no subiréis al cielo por toda la eternidad, pues se ha decretado ataros a la tierra por todos los días de la eternidad (HenEt 14,4-5).

El "discurso de Henoc", según esta tradición judía -que tuvo notable importancia en las ideas religiosas del siglo I d. C., incluso entre los cristianos ${ }^{19}$, es el anuncio de la desgracia definitiva a los "ángeles caídos". También, según la secuencia de ideas de Gn 6-8 y según consta explícitamente en la tradición judía ${ }^{20}$, esta rebelión de "los ángeles/hijos de Dios" fue la causa del diluvio, al que solo sobrevivieron Noé y su familia.

El autor de 1 Pe parece conocer esta tradición popular del judaísmo y la habría asumido, poniéndola al servicio del propio anuncio cristológico.

19 Cf. Jds 6.13 y 2 Pe 2,4 .

20 Cf. Sab 14,6; Jubileos 5; Testamento de Neftalí 3,5. 


\title{
2. 1 Pe 3,17-23 en su contexto y comentario de algunas ideas inspiradas en él
}

\author{
Felices ustedes cuando sean insultados y perseguidos, \\ y cuando se los calumnie en toda forma \\ a causa de mí... (Mt 5,11).
}

\subsection{Pe 3,17-23 en su contexto}

Parece evidente desde el inicio que la unidad 3,17-22 no va a hablar del sufrimiento en general, sino del sufrimiento "haciendo el bien", en cuanto respuesta del "bautizado/reengendrado" a la "voluntad de Dios" y -en línea con 2,19-21- ${ }^{21}$ como (otra) fundamentación a las exhortaciones a un comportamiento auténticamente cristiano, aunque se padezcan hostilidades, calumnias y pruebas, que se van a ir desarrollando a lo largo de $1,13-4,11^{22}$, y particularmente de 3,8-22.

Tras el "saludo" $(1,1-2)$ y el "prólogo" teológico-cristocéntrico $(1,3-$ 12) sigue una serie de imperativos $(1,13-2,10)$ que desarrollan una vibrante exhortación a responder en forma conveniente al don de salvación, recibido del que los "ha rescatado" de una vida inservible, necia, ilusoria, vacía (cf. $1,18)$, mediante "una sangre preciosa, como de cordero sin defecto y sin mancha" (cf. 1,19).

Se convoca a los destinatarios -y en ellos a todos los creyentes-, en virtud de la "vida nueva" que Dios -mediante la resurrección de Cristo y su

21 Pe 2,19-21: "Porque es una gracia soportar, con el pensamiento puesto en Dios, las penas que se sufren injustamente. [...] si, a pesar de hacer el bien, ustedes soportan el sufrimiento, esto sí es una gracia delante de Dios. A esto han sido llamados, porque también Cristo padeció por ustedes, y les dejó un ejemplo a fin de que sigan sus huellas" (Biblia del Pueblo de Dios).

22 Según Cervantes Gabarrón, La pasión de Jesucristo, 53-56, la unidad 3,17-22 quedaría incluida en una unidad más amplia, comprendida entre 1,13 y 4,11, en la que se desarrollaría, tras el saludo (1,1-2) y un denso prólogo teológico-cristocéntrico (1,3-12), el tema de la "regeneración" (ảvajevváw), que sería contemplada no solo como la acción transformante de Dios por la resurrección de Jesucristo $(1,3)$, sino también como un claro y potente "llamado" a responder en cualquier circunstancia al don de recibido con una "buena conducta" $(1,13-5,9)$. Otros exegetas presentan la estructura de 1 Pe basándose en las dos ocurrencias -en 2,11 y 4,12-

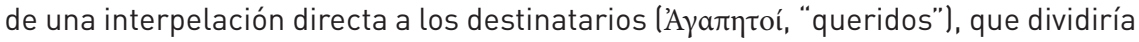
1 Pe en tres partes principales: 1,1-2,10 / 2,11-4,11 / 4,12-5,14 lasí, por ejemplo, Michaels, XXXIV-XL). Para un amplio panorama de otras propuestas de comprensión de la estructura de 1 Pe, cf., entre otros, Cervantes Gabarrón, La pasión de Jesucristo, 23-53, y WiLLIAMS, The Doctrine of Salvation, 339-349. 
Palabra eficazmente vivificadora- ha hecho germinar en todo bautizado $(1,3.23 ; 2,2)$, a una "buena conducta", a "obedecer a la verdad" $(1,22)$, a responder a la nueva condición de "renacidos/regenerados" (1,3.23), estando alerta, manteniendo la esperanza, siendo santos, procediendo con reverencia (1,13-21). Y, ya que el bautizado ha sido reengendrado de una "semilla incorruptible" que es "la Palabra viva de Dios, que permanece para siempre" $(1,23)^{23}$, se lo llama a un amor fraterno, ferviente y sincero $(1,22-$ 25) y a buscar el alimento puro de la Palabra (cf. 2,1-3, leído en referencia a 1,22-25), para "crecer" saludables "hacia la salvación" $(2,2)$. Y así Dios hará de todo bautizado, a la manera de "piedra viviente", un "templo espiritual", "para ejercer un sacerdocio santo", anunciando "las maravillas de aquel que los llamó" (2,4-10).

En la sección siguiente $(2,11-4,11)$ se mencionarán en particular diversos ámbitos "hostiles" donde todo "creyente/regenerado" -que, en cuanto tal, vive ahora como extranjero y forastero que está de paso, y por ello es objeto de calumnias- está llamado a "hacer el bien". Y, así, los que ahora "los calumnian como a malhechores" tendrán que "glorificar a Dios el día de su visita" (2,11-12; cf. 3,16b).

En 2,13-3,12 se recomienda específicamente a todos respetar toda

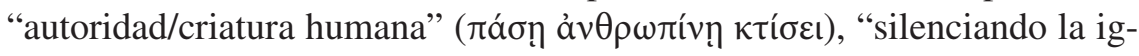
norancia de los ignorantes" (2,13-17). A los "esclavos", y en ellos a todos los creyentes, a seguir las huellas de Cristo -que llevan hacia Dios ${ }^{24}$, , "en cuya boca jamás se encontró engaño" ni "devolvía insulto por insulto", y que, "al padecer, no amenazaba" (2,18-25). A las “mujeres", en cuanto "es-

23 Observa Cervantes Gabarrón, La pasión de Jesucristo, 164: “La función mediadora de la resurrección de Cristo en la regeneración de los creyentes $(1,3)$ la desempeña en este texto la palabra viva y permanente de Dios $(1,23)$, que como semilla incorruptible expresa el origen de una nueva vida, purificada en la obediencia, para vivir en el amor mutuo $(1,22)$ [...] La cita de Is 40,6-9 en 1 Pe 1,24-25 sirve de argumento escriturístico para mostrar la vitalidad de la palabra de Dios con su potencia regeneradora".

24 Texto central de la "teología de la pasión" de la carta, que incluye en 2,21-25 -su núcleo fundamental- una lectura soteriológica y ejemplar de la "pasión de Cristo", en referencia al "Siervo sufriente" de Is $53(2,23-24)$ y al motivo del "Pastor" de Ez 34,16 (2,25), el "Pastor que vigila o guarda" las vidas de las "ovejas errantes", “descarriadas", que han vuelto a él (a Cristo, y no solamente a Dios), "siguiendo sus huellas" $(2,21)$. Esto hace de esta presentación cristológica, que relaciona el "sufrimiento de Cristo" con su compromiso radical por "hacer incansablemente el bien", algo excepcional. Cf. Cervantes Gabarrón, La pasión de Jesucristo, 331-351 lesp. 338, donde hace referencia particularmente a la tesis de E. BosetTI,

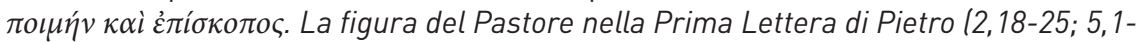
4), Roma 1988). 
posas", a "ganar", sin palabras, con su conducta, a los esposos que no fueron persuadidos por la Palabra (3,1-6). A los "varones", en cuanto "maridos" -si no quieren "obstaculizar su oración"-, a respetar a sus esposas por ser "coherederas de la gracia de la vida" $(3,7)$. A todos, a no "devolver mal por mal ni injuria por injuria", sino "bendiciendo", porque "para esto los llamaron, para que hereden una bendición" $(3,8-12)^{25}$.

La exhortación continúa dirigiéndose "a todos" a soportar los sufrimientos por la justicia, haciendo el bien como Cristo (3,13-16 / 3,17-22 / 4,1-11):

\section{3,13-16}

Siguiendo el hilo conductor del párrafo anterior sobre el "celo" por "hacer el bien" (3,13), se introduce -como se hará en 4,14- una "bienaven-

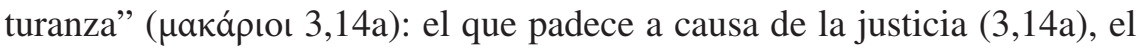
que no teme al propio miedo ( $3,14 \mathrm{~b})$, el que está pronto a manifestar la santidad del Señor en lo más profundo de su ser $(3,15 a)$ y está preparado para explicar la esperanza que anida en su interior $(3,15 b)$, ha alcanzado el nivel más alto al que puede llevar el celo por el bien, aquello que otorga la felicidad plena y definitiva. Estando bien consciente de esto y procediendo con gentileza y respeto se podrá lograr que los que maltratan y calumnian se avergüencen de aquello mismo que dicen $(3,16)$. Porque esta es la voluntad de Dios, "hacer siempre el bien", ofreciendo a quien quiera oír "palabras de esperanza".

Mediante la conjunción causal үá $\rho$ ("pues”, "puesto que”), el párrafo siguiente introducirá una "exposición explicativa" a esta exhortación, que estará centrada en "el hacer y el decir" salvífico y ejemplar del Resucitado, que alcanza hasta los "espíritus encarcelados" y que, a su vez, es el fundamento del compromiso que cada "renacido por su Palabra" adquiere desde el momento de su bautismo.

25 En 3,8-12 parece que se pretende apuntar específicamente al mal que se

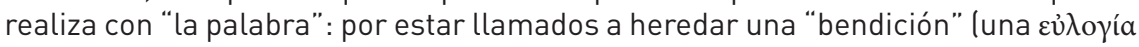
es decir, una "buena palabra") siempre se ha de responder "hablando buenas pa-

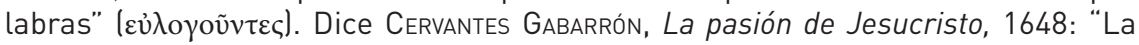
respuesta genuinamente cristiana [...] no se puede limitar a evitar el mal de palabra o de obra $(3,10-11 a)$, sino que propone un planteamiento más constructivo, se trata de responder deseando el bien al otro $(3,9 \mathrm{~b})$ y de hacer el bien $(3,11 \mathrm{~b})[\ldots]$ es que los creyentes son herederos de una bendición, de una palabra regeneradora de vida, la palabra que anuncia el nacimiento a la vida nueva por la resurrección de Jesucristo de entre los muertos." 


\section{3,17-22}

Puesto que "... es mejor padecer por obrar el bien, si esa es la voluntad de Dios, que por obrar el mal" $(3,17)$, Cristo padeció -dando ejemplo $^{26}$ - "por los pecados de los injustos", realizando en favor de ellos el máximo bien de "llevarlos a Dios" $(3,18)$.

Con una serie de oraciones subordinadas que despliegan motivos tan fragmentarios como lacónicos del AT y de la tradición judía paratestamentaria $(3,19-20)$-que se supone que el lector sabrá completar ${ }^{27}$ - se mostrará cómo ese actuar soteriológico del Señor resucitado que hay que imitar al-

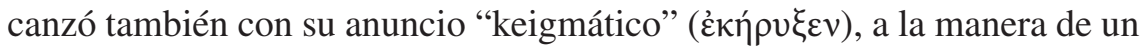
"antitipo" de $\mathrm{Henoc}^{28}$, incluso el escenario extramundano de los "espíritus encarcelados", uniendo así en el mismo destino salvífico, trascendiendo las fronteras del tiempo, del espacio y de la naturaleza humana, tanto a los "injustos" de 3,18 como a los "espíritus en prisión" y a las ocho personas que fueron preservadas del agua del diluvio de 3,19 -acontecimiento que, a su vez, prefiguran la potencia salvífica actual y permanente del bautismo $(3,21)$ -

\section{4,1-6.7-11}

La "pasión de Cristo" aparece ahora como motivación para "terminar con el pecado". Con esta "mentalidad" (عُvvola) debe "armarse"

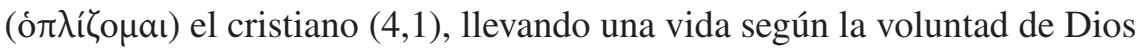
$(4,2)$, sin excesos libertinos, como en su vida anterior -aunque se blasfeme contra él $(4,4)-$, "teniendo su mente en sintonía" ( $\sigma \omega \varphi \rho o v \eta ́ \sigma \alpha \tau \varepsilon)$ con Cristo

26 “... la ejemplaridad se deduce de la conexión de 3,18 con 3,17 a través del adverbio “también' (v. 18)” (Cervantes Gabarrón, La pasión de Jesucristo, 1649).

${ }_{27}$ Si bien no parece existir una dependencia literaria directa de 1 Pe respecto del Libro de Henoc, sí es posible encontrar allí "una trama de ideas que resulta sorprendente y significativa en referencia a $1 \mathrm{Pe} 3,19 \mathrm{~s}$ ", “que influyó ciertamente en la literatura cristiana"; "los vv. 19-21 adquieren un sentido plausible partiendo de la estructura narrativa mítica del Libro de Henoc, sentido que no es posible hallar de otro modo. Ahora se puede explicar la serie de temas [...] de los vv. 19-21, y esto no es poco"; "Como en todas las frases de $1 \mathrm{Pe}$, al autor le basta aquí con algunos términos para esbozar y evocar todo un horizonte cristológico, pero que él volvió hermético con su laconismo para el lector actual" (Brox, La primera carta de Pedro, 232-234); cf. Klumbies, “Die Verkündigung”, 7, 11.

28 Con Klumbies, “Die Verkündigung” (cf. 11-13 y 17-18): “... Christus fungiert im Blick auf seine Predigt gerade als Gegentypos zu Henoch und verkündigte den gefesselten Geistern in der Tat das Evangelium" (12); "Selbst die Geister im Gefäng-

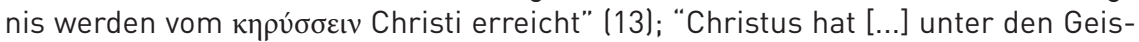
tern 'kerygmatisch' gewirkt" (17). 
y con los demás creyentes, y sobriedad para darse a la oración, practicando la hospitalidad, amando intensamente y poniendo sus dones al servicio de los demás (cf. 4,7-11). En una perspectiva clara de juicio "a vivos y muertos" $(4,5)$ se afirma el designio de vida de Dios, que es eficaz y es capaz de llegar, "evangelizando", más allá de la muerte $(4,6)$, en contraposición a la idolatría y a los deseos desenfrenados de los que ahora los hostigan resentida y burlonamente, quienes, vivos o muertos, tendrán que rendir cuentas ante Juez escatológico (4,2.3-4).

Antes del epílogo teológico-doxológico $(5,10-11)$ y del final epistolar $(5,12-14)$ se vuelve a exhortar a la alegría ante la prueba del sufrimiento en comunión con Cristo y se ofrecen recomendaciones finales a ancianos, jóvenes y a todos en general $(4,12-5,9)$.

\title{
2.2. Comentario de algunas ideas inspiradas en 1 Pe 3,17-22. Llamados a "hacer y decir el bien", con una Palabra que es capaz de actuar más allá de las fronteras del tiempo y del espacio
}

\author{
... han sido engendrados de nuevo, \\ no por un germen corruptible, sino incorruptible: \\ la Palabra de Dios, que vive y permanece... (1 Pe 1,23). \\ ... bendigan a los que los maldicen, \\ rueguen por los que los maltratan... (Lc 6,28).
}

La importancia de la Palabra de Dios, "que vive y permanece" $(1,23)$ y hace posible la respuesta de fe, cuyo término es la salvación (cf. 1,9)-Palabra que tiene el mismo potencial regenerador que la resurrección del Señor $(1,3.23)$ y que es tan "buena noticia" que hasta "los mismos ángeles anhelan asomarse a contemplar" $(2,12 b ; 1,25)-$, el valor de conocerla y anunciarla siempre, "siguiendo las huellas de Cristo", sin temores ni restricciones, aunque haya que padecer injurias y hostilidades, aunque haya que vivir como extranjero y forastero en la propia casa $(1,1 ; 2,11)$, son también temas medulares en 1 Pe que van emergiendo de una u otra manera a lo largo del desarrollo.

Para anunciarla con eficacia y sin desfallecer, con coraje y convicción, se exhorta a conocerla "con"-“ciencia", como los profetas que la profetizaron, que, aun sabiendo que el mensaje al que servían no era para ellos $(1,12$; cf. 1,5), lo investigaron, indagaron e hicieron objeto de cuidadosa búsqueda $(1,10)$, tratando de descubrir cómo y cuándo habría de ocurrir esa salvación que anunciaban y que "el Espíritu de Cristo que estaba en ellos"

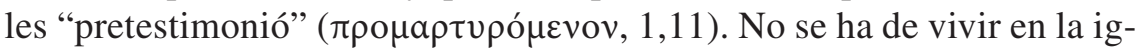


norancia $(1,14)$, sino en la obediencia a la verdad $(1,22)$, sin dolo ni hipocresía $(2,1)$, deseando el alimento no adulterado que procede de la Palabra $(2,2)$, si es que se gustó "lo bueno que es el Señor" (2,3). Obrando el bien conforme a ella es como se ha de acallar la ignorancia de los insensatos $(2,15)$. Y solo así se podrá estar convenientemente preparado, teniendo todos los mismos pensamientos y afrontando de manera semejante las dificultades (ó $\mu$ ó $\varphi \rho o v \varepsilon \varsigma, 3,8$ ), para defender la propia la esperanza ante quien lo pida $(3,15)$.

Esa Palabra que, a pesar de los padecimientos, ha sido tan sólidamente incorporada en la nueva vida del bautizado, que la sigue anhelando con la avidez de un lactante (2,2), permanece constantemente operante en él (cf. $1,23-25)$ y lo hace capaz no solamente de "hacer el bien" $(2,15.20 ; 3,6$;

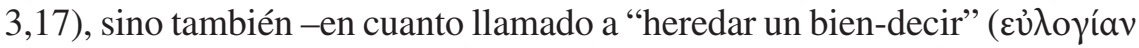

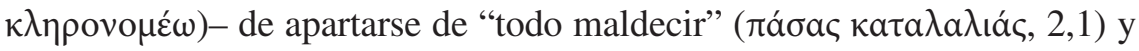

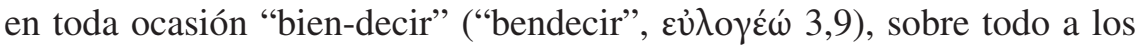
que más dañan, con palabras agraviantes $(3,9)$, abusando de los más vulnerables e indefensos (como los esclavos y las mujeres). De ahí también el amplio recurso al Salmo (LXX) 33,13-17 -con su exhortación a "guardar la lengua del mal"- en la argumentación (3,10-12).

También con una "buena palabra" que es capaz de salvar, de reengendrar, llegó Cristo hasta los "espíritus en prisión”, que, según las leyendas paleojudías, tanto daño hicieron a la humanidad. 1 Pe 3,20 afirma que

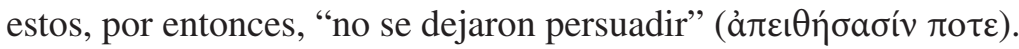

En el presente de la comunidad también hay muchos que dañan por "no dejarse persuadir". Los destinatarios de la carta están llamados a actuar en favor de ellos, sin desfallecer, con sus buenas acciones y con sus buenas palabras.

Son aquellos que, por "no dejarse persuadir por la Palabra" ( $\tau \tilde{\omega}$

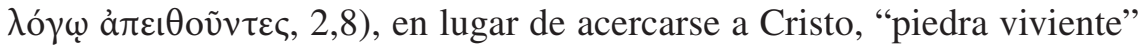
-"colocada en Sion" como "piedra angular", "elegida", "altamente estimada"-, la rechazan, tropiezan en ella. En cambio, "los que creyeron en él nunca serán confundidos" y están llamados a "anunciar", también a ellos, las maravillas del que los "llamó de las tinieblas a su admirable luz" (cf. 2,4-10).

En el presente de la comunidad hay también esposos que "no se de-

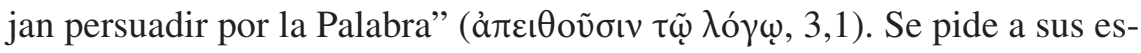
posas creyentes la aceptación pacientemente activa de situaciones -no siempre agradables, se infiere- a fin de poder "ganarlos", si no con palabras, al menos con una conducta testimonial, capaz de "bien decir" sin palabras. 
Hay seres que, en el presente de la comunidad, por no "dejarse persuadir entonces" se los tenía por irremediablemente condenados (3,20). A los destinatarios de la carta se les hace saber que Cristo ha llegado ejemplarmente hasta ellos con su potente Palabra vivificadora, y que la esperanza también es posible para ellos.

Finalmente, ante la perspectiva del "juicio", habría quienes, en el presente de la comunidad, se habrían preguntado tal vez por la suerte de

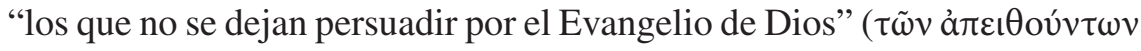

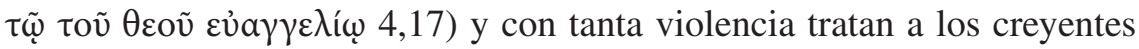
por el mero hecho de serlo (cf. 4,12-19). El texto recuerda al creyente aún vivo que debe confiar la propia vida -amenazada, quizá- al Creador y continuar haciendo el bien $(4,19)$, y que si el violento dejó esta vida sin haberse dejado persuadir por el Evangelio, tendrá ocasión de oírlo en la otra, de labios del mismo Señor $(4,6)$.

En definitiva, porque en eso consiste, según 1 Pe, el bautismo, "un compromiso público con Dios [que proviene de] estar bien consciente" de la presencia operante de Dios y su Palabra en la propia vida, y del deber de responder convenientemente a ese don, recibido por la resurrección de Jesucristo, en cualquier circunstancia, por violenta, amenazadora o desagradable que se pueda presentar $(3,21)$.

\title{
3. Algunas reflexiones al final del recorrido
}

\author{
Que nuestro Señor Jesucristo y Dios, nuestro Padre, \\ que nos amó y nos dio gratuitamente \\ un consuelo eterno y una feliz esperanza, \\ los reconforte y fortalezca en toda obra y en toda palabra buena (2 Tes 2,16-17).
}

Nos parece notable la forma como 1 Pe exhorta a mantenerse firme y conscientemente fiel al compromiso testimonial que cada bautizado ha adquirido con Dios desde el momento en que ha quedado vinculado a él en forma definitiva por sus promesas bautismales, promesas que le obligan internamente -“isantifiquen al Señor en su corazón!”, “imanifiesten su santidad!” (3,15a) - a adoptar comportamientos alternativos visibles en orden a revelar en toda ocasión, por adversa que sea, el don de la vida nueva recibida por la resurrección de Jesucristo y su Palabra regeneradora, siendo siempre capaz de ofrecer palabras de esperanza a quien quiera que lo pida $(3,15 b)$. También nos resulta notable cómo el autor de 1 Pe afirma con tanta claridad que la Palabra y la resurrección de Cristo son capaces de operar más allá de cualquier límite espacial, temporal o humano $(3,19-20)$, y aun después de la muerte $(4,6)$. 
A propósito de esto último, 1 Pe no es el único texto neotestamentario que manifiesta una inquieta curiosidad por la posibilidad de experimentar la influencia del poder salvífico de Cristo en personas ya fallecidas, sean bautizadas, pertenecientes a la comunidad cristiana (como parece inferirse del planteo de 1 Tes 4,13-17) o no (como parece ser el caso de la práctica corintia mencionada en 1 Cor 15,29 de "bautizarse por los muertos" $)^{29}$.

Sea que se haya pensado que estar ya muerto podría ser un obstáculo para el pleno encuentro con el Señor en su "venida" (como parece haber ocurrido en Tesalónica), sea que se haya temido que seres queridos o simples conocidos que murieron sin estar bautizados pudieran quedar excluidos de la resurrección (y por ello se habría incorporado la práctica de algo así como un "bautismo vicario", como parece haber ocurrido en Corinto), sea que se haya pensado que los que atormentaron y vejaron a los cristianos solo por el hecho de serlo y murieron sin haberse dejado persuadir por el Evangelio podrían estar condenados sin esperanza (como quizá pudieron sospechar algunos de los destinatarios de $1 \mathrm{Pe}$, a quienes se asegura que el Evangelio se sigue predicando después de la muerte, dando a todos la posibilidad de acceder por la fuerza del Espíritu a la vida de Dios, cf. 4,6), sea incluso que se haya pensado en seres a los que se tenía por definitivamente condenados, sin que nada en favor de ellos se pudiera ya realizar (cf. $1 \mathrm{Pe}$ 3,19-20), $1 \mathrm{Pe}-\mathrm{y}$ parte considerable de la reflexión cristiana primitivaasegura que Cristo tiene acceso salvífico a todos los ámbitos existenciales, los cósmicos y los humanos, del más acá y del más allá, del presente inmediato, del pasado remoto y del futuro por construir, de los justos acosados y de los impíos contumaces -o ya sin esperanza-, y que puede obrar sin restricciones en sus existencias, ofreciendo generosamente la vida nueva que germina a borbotones de su Palabra buena y de su gloriosa resurrección.

Claudia Mendoza Universidad Católica Argentina

29 Ideas inspiradas en las reflexiones de KLumBIEs, “Die Verkündigung”, 13, 18-23. 